\title{
The use of e-learning by students in Iraqi universities: Potential and challenges
}

\author{
Nisreen Ameen \\ Lord Ashcroft International Business School, Anglia Ruskin University, Cambridge, UK \\ Email: nisreen.ameen@student.anglia.ac.uk \\ Robert Willis \\ Lord Ashcroft International Business School, Anglia Ruskin University, Cambridge, UK \\ Email: rob.willis@anglia.ac.uk \\ Media Noori Abdullah \\ Salahaddin University, Erbil, Kurdistan, Iraq \\ Email: media.abdullah@su.edu.krd
}

doi: $10.23918 /$ vesal2017.a27

\begin{abstract}
This paper investigates the potential and challenges associated with the use of e-learning in Iraqi higher education universities from the perspective of Iraqi university students. A total of 300 questionnaires were distributed to students in Salahaddin University in Iraq. 181 completed questionnaires were collected. The questionnaires included open-ended questions in which students were asked to provide their opinions on the importance and advantages of e-learning and how it can be successfully implemented in Iraq. In addition, they were asked to identify the challenges facing the use of e-learning systems in Iraqi universities. The results revealed that students are aware of the importance and benefits of e-learning for their studies. However, major challenges associated with the general infrastructure and the support provided by universities and policy making in Iraq in relation to e-learning exist. The results also revealed that Iraqi students prefer the hybrid approach of learning, using mobile phones rather than relying solely on online learning using computers.
\end{abstract}

Keywords: Avicenna Virtual Project, E-learning, Salahaddin University

\section{INTRODUCTION}

The advancement of Information and Communication Technologies (ICTs) and the Internet contributed to the improvement of teaching and learning by moving from the traditional ways of teaching to new methods in which technology is integrated within the teaching and learning process. The term e-learning was defined by Mikic and Anido (2006) as the "Use of internet technology for the creation, management, making available, security, selection and use of 
educational content to store information about those who learn and to monitor those who learn, and to make communication and cooperation possible". E-learning systems have been used successfully in universities in developed countries and some Arab countries for example Jordan and UAE. However, the use of e-learning in Iraqi universities is behind in comparison to other Arab countries.

Previous studies investigated the use, implementation, benefits and challenges of e-learning in Iraq in general from the perspectives of experts and lecturers (Elameer and Idrus, 2010; Anter et al., 2014; Fahad et al., 2015; Thabit and Harjan, 2015). However, none of these studies investigated the potential and challenges of using e-learning systems in Iraqi universities based on students' opinions. Although the opinions of experts in the field are important and can certainly provide important views, students are the end users of the system. Therefore, understanding students' views and opinions is crucial. There is a lack of research on how university students in Iraq view e-learning to understand their opinions on the benefits, potential, importance and the use of elearning in universities and the challenges facing its successful implementation. There are several factors that can affect students' intentions towards the use of e-learning ( $\mathrm{Li}$ et al., 2012). Previous studies found that the key factor for the successful implementation of e-learning systems is the presence of a supportive culture for e-learning among students (Kwofie and Henton, 2011; Almarabeh and Mohammad, 2013). Since the successful implementation of an e-learning system is highly dependent on students' perceptions towards it, understanding what they think of their use of the e-learning system at their university and what can contribute to its successful implementation is important. Therefore, the main aim of this research is to investigate the potential of and challenges facing the successful use of e-learning systems in Iraqi universities from the students' perspective. The results of this research can help universities, governments and policy makers to enhance the use of e-learning in Iraq by understanding the students' (end users of the system) views on this subject. This research is also important because the area of e-learning in Iraq is under researched. The main objectives of this research are:

1. To identify the advantages that e-learning can bring to higher education in Iraq from the students' perspectives.

2. To understand the perceptions of Iraqi university students on how the use of e-learning systems can be successful in Iraq.

3. To identify the challenges facing the use of e-learning systems in Iraqi universities from the students' perspectives.

\section{THE STATUS OF E-LEARNING IN IRAQ}

In comparison to other Arab countries, launching e-learning systems in Iraq came at a late stage. Although universities in Iraq are interested in online learning, they have only started using it recently. Previous studies showed that universities are aware of the importance of e-learning 
(Fahad et al., 2015; Ameen and Willis, 2016). In 2010, a new project, the Avicenna Virtual campus, was launched in Iraq to integrate e-learning systems in higher education (Ameen and Willis, 2016). The project was based on an agreement between the United Nations Educational Scientific and Cultural Organisation (UNESCO) and the Ministry of Higher Education in Iraq, to be implemented in three Iraqi universities namely Baghdad, Basrah and Salahaddin universities. The e-learning system was introduced in these universities in 2015. The project will allow Iraq to join 14 other countries that have the same project with the UNESCO (Su.edu.krd, 2016). Thabit and Harjan (2015) evaluated the e-learning system at Avicenna Centre in Erbil with reference to Khan's eight dimensional e-learning framework. The data were collected from staff members and academics. The results showed that there are some gaps mostly in terms of the ethical dimension, the evaluation dimension and the management dimension.

Recent studies in Iraq showed that Iraqi universities are interested in integrating e-learning systems as part of their programme (Fahad et al., 2015). However, there is a lack of experience and effective planning of e-learning systems in most Iraqi universities (Elameer and Idrus, 2010). Elameer and Idrus (2010) highlighted the main benefits e-learning can bring for Iraqi universities. E-learning can fill many gaps that exist in Iraqi universities such as; overcoming the incapability of some of the universities' staff members to create online materials for the purpose of complementing the students' in-class learning, enhancing a more student-centred education and addressing the lack of up-to-date materials and advance the students' learning experience using the latest ICTs in order for Iraqi students to be considered well-educated in comparison to students in other parts of the world (Elameer and Idrus, 2011).

\section{THE IMPORTANCE OF E-LEARNING}

Bhuasiri et al., (2012) identified the main advantages of the use of e-learning systems. The authors stated "Advantages of e-learning for learners include an increased accessibility to information, better content delivery, personalized instruction, content standardization, accountability, on demand availability, self-pacing, interactivity, confidence, and increased convenience" (Bhuasiri et al., 2012). Perhaps one of the most important advantages of the use of e-learning is that it enables students to become independent thinkers since the reliance on their tutors is kept to the minimum when learning online. The integration of e-learning in higher education proved to be crucial in terms of increasing both flexibility and accessibility (Ameen and Willis, 2016). Students can learn at their own time and availability (Kwofie and Henten, 2011). Students can access the e-learning platform at any time and any place (Almarabeh and Mohammad, 2013; Ameen and Willis, 2016). The integration of e-learning in higher education is even more significant in developing countries than the developed countries. Since this study is concerned with the development and use of elearning systems in Iraq- a developing country from the higher education institutions perspective, it can be argued that the two major advantages of incorporating e-learning systems into teaching can be the improved quality of education and the decreased cost. The use of e-learning to complement the traditional methods (face-to-face) of teaching allows students to access online 
books, up-to-date journals and articles, lecture slides and use videos and other online materials. The fact that students learn online and they are not required to be physically present at their university campus does not mean that they will be isolated from their lecturers and other students. E-learning platforms allow the use of online tutorials and blogs where students can comment on different topics or ask and answer questions online, meaning that communication can change to be online (Unwin, 2008).

\section{CHALLENGES OF E-LEARNING IMPLEMENTATION}

The difference in culture between Western and Eastern countries is a major challenge facing elearning adoption that was acknowledged in previous studies (Andersson and Grönlund, 2009). The reason behind this can be that e-learning systems are usually developed in countries with advanced capabilities in terms of Information and Communication Systems (ICTs) where students are highly exposed to technology. When these systems are implemented in less advanced countries where students are less exposed to technology, new challenges are introduced.

Based on their extensive literature review, Andersson and Grönlund (2009) categorised the challenges facing e-learning use into four main categories namely; course challenges, challenges related to characteristics of the individual (student or teacher), technological challenges and contextual challenges (organisational, cultural and societal challenges). We conducted an analysis of the most recent studies on the use of e-learning systems in developing countries in which barriers facing the use of e-learning systems were identified. Some areas are considered as major barriers to the successful implementation of e-learning systems in Arab countries in general and in Iraq. These challenges are namely infrastructure, the culture of teaching and learning, the design and support of the system and students' readiness.

\subsection{INFRASTRUCTURE}

The lack of electricity, computers and the Internet is a major challenge facing the successful implementation of e-learning in developing countries (Rajesh, 2003; Eke, 2011). In fact, these issues are present in Iraq. The unstable political and economic situation that Iraq has been through had a significant impact on the infrastructure as a whole in terms of the essential services that should be available to Iraqis and the technological infrastructure of the country. The country has suffered from the lack of electricity for years and the problem still exists (Al-Khatteeb and Istepanian, 2015). Furthermore, only $12 \%$ of the total population has a personal computer (UNDP, 2015). On the other hand, $78 \%$ of the total population use mobile phones (UNDP, 2015). Previous studies found that mobile learning can be used successfully in education (e.g. Ozdamli and Uzunboylu, 2015). This means that it may be possible that using mobile learning would be more

successful than using e-learning on its own since the younger generation owns more mobile phones than computers. 


\subsection{THE CULTURE OF TEACHING AND LEARNING}

Culture has an influence on the acceptance and use of e-learning systems (Tarhini et al., 2015). The culture of teaching and learning in developing countries is certainly different from the culture in developed countries. This is due to differences in the characteristics of the culture in different countries (Hofstede, 2001). In general, the culture in Iraq is high in power distance (GreetHofstede, 2016). Within this culture, students view lecturers as the main source of information for their learning and they rely heavily on them in their learning progress (Andersson and Grönlund, 2009). This situation offers both challenges and advantages. When students have high reliance on lectures, they may not prefer to move away from the traditional ways of teaching (i.e. face-toface). However, in high power distance and collectivistic societies such as the society in Iraq (Greet Hofstede, 2016), younger people (i.e. students) tend to respect and listen to the elderly (i.e. lecturers) and follow their advice and guidance. Consequently, social influence can be strong in such a culture so when lecturers advise students on the use of the available e-learning platforms at their university, students may very well start using them.

\subsection{THE DESIGN AND SUPPORT OF THE SYSTEM}

The majority of developing countries lack the presence of expertise in the planning and implementation of the most up-to-date technologies (Qureshi et al., 2012). This has an effect on the design of the system, its interface and usability. In fact, the challenges can adversely affect the interface (design of the system) and the quality of the content provided to students via the online platform (Kwofie and Henten, 2011). Studying online means that students will not be able to ask the questions they normally ask when they learn during their physical presence in class. Therefore, the inclusion of the right content at the right time is crucial.

The presence of an efficient system design and interface that can motivate students becomes even more important when students have no or little experience in using technology in general and specifically using technology for education (Picciano and Seaman, 2007; Al Obisat et al., 2013). The difficulties in using the system can be reduced with the presence of a technical support team that works efficiently and understands that students have no or little experience in using the system.

\subsection{STUDENTS' READINESS}

Since students are the end-users of the e-learning system, they are the core element in the process of its adoption and efficient use (Andersson and Grönlund, 2009; Chanchary and Islam, 2011). Students' motivation to use a new system is an important factor. Also, the familiarity of students 
with technology and the use of computers is lacking among students in Iraq. The lack of computer skills due to the low use of computers (Heshmati et al., 2013) especially for educational purposes is a factor that can affect students' confidence towards system's use (Kwofie and Henten, 2011).

\section{METHODOLOGY}

The sample included students from different faculties in Salahaddin University in Erbil/Iraq. Salahaddin University is a leading university in Iraq. It was the first university in Kurdistan region (the northern part of Iraq) to adopt e-learning systems as part of a project between the UNESCO and the Iraqi ministry of higher education. Data were collected from students via the distribution of 300 questionnaires using convenience sampling.

The first section of the questionnaire included questions on the students' demographic information including age, gender and their faculty. The second section included closed-ended questions to ask students whether they think that they are using the current e-learning system effectively, and whether it is easier for them to access the electronic portal using their mobile phones or a computer. Also, they were asked whether they have a computer at home that can be used to access the portal. They were also asked about their preferred method of learning. The third section included openended questions to investigate students' perceptions on the importance and advantages of the elearning system. Also, this section included questions on how they think the use of e-learning can be successful and their opinions on the main challenges facing the use of e-learning systems in universities in Iraq.

The answers to the closed-ended questions were analysed using descriptive statistics in SPSS. The answers to the open-ended questions included qualitative data but they were analysed quantitatively by categorising and coding them. The coding of the responses to the open-ended questions was carried out manually then SPSS was used.

\section{ANALYSIS OF THE RESULTS}

The total number of completed questionnaires was 181 questionnaires. (43\%) of the respondents were males and $(57 \%)$ were females. The participants were between the ages of 18 to 37 years old. Most of the participants were undergraduates (89.5\%). The remaining were postgraduates (10.5\%). The majority of the students were in the faculty of business $(64 \%)$, followed by the faculty of law $(30 \%)$ and the faculty of computing science and engineering $(6 \%)$. 
(43\%) of the respondents thought that they were using the e-learning system effectively while $(47 \%)$ of them thought that they were not use it effectively. (70\%) of the students thought that mobile phones are easier to access the electronic portal while only (30\%) of them thought that it is easier to access it using their computers. With regards to their preferred method of learning, (13\%) preferred face-to-face learning, (6\%) only preferred online learning and (81\%) preferred the hybrid approach to learning. (90\%) of the students had computers at home and (10\%) did not have any.

The results showed that the participants were aware of the importance of e-learning for their studies. Most of the participants think of e-learning as a modern way of learning (98\%). (94\%) of the participants thought that it is important because it is good for saving time and offering more flexibility. Most of them (97\%) also indicated that it is important for obtaining information. Participants were also asked to state the advantages e-learning can offer them. (92\%) of them stated that it provides more information in relation to their studies than the traditional method of learning. (71\%) of them stated that it helps to obtain up-to-date information. A small percentage of them (14\%) stated that it helps in learning through online courses provided abroad which students can study while they are in Iraq. On the other hand, a high percentage of them (95\%) stated that it is a less costly and a more convenient way of learning. When students were asked about the successful implementation of e-learning, $(88 \%)$ of them stated that there is a need for preparing the right facilities and computers to accommodate e-learning while (96\%) of them stated that e-learning can be successful by providing a constant supply of electricity, improving the speed of the Internet (94\%) and providing good guidance and instructions on how to use the electronic portal (42\%). The majority of the participants (99\%) stated that the implementation of online learning can be successful when online courses become officially certified and recognised by the Ministry of Higher Education in Iraq.

Many challenges were listed by the participants. Most of the participants (99\%) stated that the major challenge facing the use of e-learning is that the qualifications obtained from studying online courses cannot be certified by the Ministry of Higher Education. This was followed by the lack of electricity (96\%), the slow speed of the Internet connection (94\%), lack of access to the Internet (91\%), lack of facilities provided by the university (90\%), high cost of the Internet (90\%), lack of culture that promotes the use of technology for learning (86\%) and a small number of them (22\%) stated that the lack of knowledge on how to use the system is also an issue. 
Table 1: Results of descriptive statistics

\begin{tabular}{|c|c|c|}
\hline Importance & Frequency & Percentage \\
\hline - It is a modern way of learning & 178 & $98 \%$ \\
\hline - It is good for saving time and more flexible & 171 & $94 \%$ \\
\hline - It is important for obtaining information & 176 & $97 \%$ \\
\hline Advantages & Frequency & Percentage \\
\hline - It provides more information than the traditional way of learning & 167 & $92 \%$ \\
\hline - It helps in obtaining up-to-date information & 130 & $71 \%$ \\
\hline $\begin{array}{l}\text { - It helps in leaming through online courses provided by institutions in } \\
\text { other countries while students are based in Iraq }\end{array}$ & 25 & $14 \%$ \\
\hline - $\quad$ Costs reduction and convenience & 172 & $95 \%$ \\
\hline Successful implementation of e-learning & Frequency & Percentage \\
\hline $\begin{array}{l}\text { - By preparing the right facilities and computers to accommodate e- } \\
\text { learning }\end{array}$ & 160 & $88 \%$ \\
\hline - $\quad$ By providing electricity constantly & 173 & $96 \%$ \\
\hline - By improving Internet speed & 171 & $94 \%$ \\
\hline $\begin{array}{l}\text { - By providing good guidance and instructions on how to use the electronic } \\
\text { portal }\end{array}$ & 76 & $42 \%$ \\
\hline $\begin{array}{l}\text { - When the qualifications obtained through online courses become } \\
\text { officially certified and recognised by the Ministry of Higher Education. }\end{array}$ & 180 & $99 \%$ \\
\hline Challenges & Frequency & Percentage \\
\hline - $\quad$ Bad Internet connection and slow speed & 170 & $94 \%$ \\
\hline - Lack of facilities provided by the university & 161 & $90 \%$ \\
\hline - Lack of electricity & 173 & $96 \%$ \\
\hline - Lack of a culture that promotes the use of technology for learning & 155 & $86 \%$ \\
\hline - High cost of Internet & 162 & $90 \%$ \\
\hline - Lack of access to the Internet & 165 & $91 \%$ \\
\hline - Lack of knowledge on how to use the system & 40 & $22 \%$ \\
\hline $\begin{array}{l}\text { - Qualifications obtained through online courses are not certified by the } \\
\text { Ministry of Higher Education in Iraq }\end{array}$ & 179 & $99 \%$ \\
\hline
\end{tabular}

\section{DISCUSSION}

The main aim of this research was to identify the importance, benefits and challenges facing a successful implementation of e-learning in Iraq based on the opinions of university students. The findings of this research extended the findings of previous studies concerned with e-learning in Iraq namely Elameer and Idrus (2010), Elameer and Idrus (2011), Anter et al., (2014) and Fahad et al., (2015). 
The majority of students seem to understand the importance of e-learning for their studies as a modern way of learning that can complement the traditional methods of learning but not rely solely on online learning. The reason behind this could be that more than half of them think that they are not using the online learning system effectively which does not encourage the full reliance on elearning. Most of the students think that online learning is important as it saves time and it is more flexible. This confirms the findings of previous studies (Almarabeh and Mohammad, 2013; Ameen and Willis, 2016). Most of the students also found that it is important for obtaining information which may not be easy to obtain otherwise which was stated in Bhuasiri et al's (2012) study.

Students find that one of the main advantages of e-learning is cost reduction in terms of travelling to university and the convenience provided which was also identified by Kwofie and Henten (2011) and Bhuasiri et al., (2012). This was also followed by the ability to obtain more information which is up-to-date through e-learning and the Internet which was also identified in Bhuasiri et al's (2012) study. A small number of students thought that learning online helps to study with institutions based abroad while still being able to live in their country which is also related to convenience in a way.

The majority of the students think that online learning can only be successful in Iraq when the Ministry of Higher Education starts to recognise and certify the qualifications obtained through these courses. This is a major issue highlighted by most students. This was followed by the need of constant electricity supply and the slow Internet speed which was also highlighted in Rajesh (2003) and Eke's (2011) studies as major issues facing a successful implementation of e-learning. In addition, students stated that the successful implementation of e-learning needs the preparation of the right facilities and computers by universities to accommodate e-learning. This possibly justifies students' preference of the use of mobile phones in learning instead of computers.

The students identified eight main challenges facing the use of e-learning in higher education in Iraq. The majority of students think that the inability to certify qualifications obtained from online courses by the Ministry of Higher Education in Iraq is a major challenge facing the use of elearning. This was followed by the lack of electricity, bad Internet connection, lack of access to the Internet, lack of facilities provided by universities, high cost of the Internet, lack of a supportive culture that promotes the use of e-learning and the lack of knowledge on how to use the system. Many of the challenges stated by the students are strictly related to the general infrastructure in Iraq namely the lack of electricity, bad Internet connection, lack of access to the Internet and high cost of the Internet. These issues are related to the use of ICTs in general but they also adversely affect the use of e-learning in higher education in Iraq. The remaining challenges are related to the support provided by universities and policy makers in the Ministry of Higher Education. 
The main implications of this research for practice and policy are summarised below;

- The Iraqi Ministry of Higher Education should recognise and certify qualifications obtained from online courses.

- The required infrastructure should be in place including electricity supply and a strong Internet connection as well as ensuring that the Internet is provided at a reasonable cost to students.

- Universities should provide the right facilities and computers to students.

- There is a need for a culture that can support and promote the use of e-learning among students.

- A team of experts should be available to students when they need assistance.

- Mobile learning should be supported in universities.

\section{CONCLUSIONS}

This study investigated Iraqi students' opinions on the potential and challenges related to the use of e-learning systems in Iraq, a country in which the concept of e-learning is still new. This was based on students' views and opinions as they are the end users of the system. The research provided important insights to universities and policy makers which must be taken into consideration in order for e-learning to be successfully used in by university students in Iraq.

The data in this research were collected from students in one university in Iraq only. The inclusion of students from other Iraqi universities that are using the e-learning system would have increased the validity of the results of this research. In addition, the final sample size (180 students) is considered low. Future studies can collect data from more universities in Iraq, using a higher sample size. In addition, future studies should be conducted by gathering information from policy makers in the Ministry of Higher Education to investigate the reasons behind the lack of recognition of qualifications obtained through online courses in Iraq and find solutions to this problem. Furthermore, future studies should investigate the reasons behind the low Internet speed which was identified by students as a major barrier to online learning and propose solutions to this problem. 


\section{ACKNOWLEDGEMENTS}

This research paper is made possible through the help and support provided by Salahaddin University/Erbil in which the primary data for this research where collected.

\section{REFERENCES}

Almarbeh, T. \& Mohammad, H. (2013). E-learning in the Jordanian Higher Education System: Strengths, weaknesses, opportunities and threats. Journal of American Science, 9, 3, 281-287. Retrieved from http://eacademic.ju.edu.jo/t.almaraabeh/_layouts/mobile/view.aspx?List=e6308ff0-a9f547ec-ae3f-983e2c2d0a33\&View=126642c0-e8e1-479b-9069-c6ab2d6b3693

Ameen, N. \& Willis, R. (2016). An investigation of the adoption of educational technology in Iraqi Higher Education: evidence from Salahaddin University. UKAIS Conference proceedings, Oxford, paper 10. Retrieved from http://dwastell.org/UKAIS2016/index.php/proceedings

Andersson. A. \& Grönlund, $\underline{\AA}$. (2009). A conceptual framework for e-learning in developing countries: a critical review of research challenges. Electronic Journal of Information Systems in Developing Countries (IJISDC), 38, 8, 1-16. doi:10.1007/s11528-008-0135-z

Anter, S., Abualkishik, A., AlMashhadany, Y. (2014). Proposed E-learning system for Iraqi Universities. International Journal of Scientific and Research Publications, 4, 5, 1-7. Retrieved from http://www.ijsrp.org/research-paper-0514/ijsrp-p2993.pdf

Al-Khatteeb, L. \& Istepanian, H. (2015). TURN A LIGHT ON: ELECTRICITY SECTOR REFORM IN IRAQ. Brookings Doha Centre. Retrieved from http://www.brookings.edu/ /media/research/files/papers/2015/03/18-electricity-sectorreform-iraq-alkhatteeb-istepanian/alkhatteeb-istepanian-english-pdf.pdf

Al Obisat, F., Airawashdeh, H., Altarawneh, H. \& Altarawneh, M. (2013). Factors Affecting the Adoption of E-Learning: Jordanian Universities Case Study. Computer Engineering and Intelligent Systems, $4, \quad 3, \quad 32-40 . \quad$ Retrieved from http://www.iiste.org/Journals/index.php/CEIS/article/viewFile/4625/4705

Bhuasiri, W., Xaymoungkhoun, O., Zo, H., Rho, J. \& Ciganek, A. (2012). Critical success factors for e-learning in developing countries: A comparative analysis between ICT experts and faculty. Computers \& Education, 58, 843-855. doi>10.1016/j.compedu.2011.10.010

Chanchary, F., \& Islam, S. (2011). IS SAUDI ARABIA READY FOR ELEARNING? - A CASE STUDY. Department of Computer Science, Najran University, Najran, Saudi Arabia. Retrieved from http://www.nauss.edu.sa/acit/PDFs/f2534.pdf

Eke, H. (2011). Modeling LIS Students' Intention to Adopt E-learning: A Case from University of Nigeria, Nsukka. Library Philosophy and Practice (e-journal), paper 478. Retrievedfrom http://digitalcommons.unl.edu/cgi/viewcontent.cgi?article=1496\&context=libphilprac 
Elameer, A. \& Idrus, R. (2010). The Readiness for an e-Learning System in the University of Mustansiriyah (OuMust) Baghdad-Iraq. Malaysian Journal of Educational Technology, 10, 2, 31-41. Retrieved from http://www.mojet.net/

Fahad, A., Hassan, Z., Sulaiman, R. \& Rahman, Z. (2015). Usability Evaluation of E-Learning Systems in the Iraqi Higher Education Institutions. International Journal of Internet of Things, 4, 1A, 30-34. doi:10.5923/c.ijit.201501.05

Greet Hofstede (2016). What about Iraq?. Retrieved from http://geert-hofstede.com/iraq.html

Heshmati, A., Al-Hammadany, F. \& Bany-Mohammed, A. (2013). Analysis of Internet Usage Intensity in Iraq: An Ordered Logit Model. Journal of Knowledge Management, Economics and Information Technology, 3, 3, 1-21. Retrieved from https://ideas.repec.org/a/spp/jkmeit/1376.html

Hofstede, G. (2001). Culture's consequences: Comparing values, behaviour, institutions and organizations across nations. Thousand Oaks, CA: Sage.

Kwofie, B., \& Henten, A. (2011). The advantages and challenges of e-learning implementation: The story of a developing nation. Paper presented at WCES-2011 3rd World Conference on Education Sciences, Bahcesehir University, Istabul, Turkey. Retrieved from http://vbn.aau.dk/files/60337174/The_advantages_and_challenges_of_e_learning_implemen tation_The_story_of_a_developing_nation.pdf

Li, Y. Duan, Y., Fu, Z. \& Alford, P. (2012). An Empirical Study on behavioural intention to reuse e-learning systems in rural China. British Journal of Educational Technology, 43, 933-948. doi: 10.1111/j.1467-8535.2011.01261.x

Mikic F., \& Anido L. (2006). Towards a standard for mobile technology. Proceedings of the International Conference on Networking, International Conference on Systems and International Conference on Mobile Communications \& Learning Technologies (ICNICONSMCL'06) -00, 217- 222

Ozdamli, F. \& Uzunboylu, H. (2015). M-learning adequacy and perceptions of students and teachers in secondary schools. British Journal of Educational Technology, 46, 1, 159-172. doi: $10.1111 /$ bjet.12136

Picciano, A., \& Seaman, J. (2007). K-12 online learning: A survey of U.S. school district administrators. New York, USA: Sloan-C

Qureshi, I., Ilyas, K., Yasmin, R, Whitty, M. (2012). Challenges of implementing e-learning in a Pakistani university. Knowledge Management and E-Learning: An International Journal, 4, 3, 310-324. Retrieved from http://www.kmel-journal.org/ojs/index.php/onlinepublication/article/viewArticle/174

Rajesh, M. (2003). A Study of the Problems Associated with ICT Adaptability in Developing Countries in the Context of Distance Education. The Turkish Online Journal 
of Distance Education, 4 (2), 1-12. Retrieved from https://doaj.org/article/ada444f5ed7c48b3baa4a6d555050a10

Su.edu.krd (2016). IRAQ JOINS AVICENNA VIRTUAL CAMPUS. Retrieved from http://su.edu.krd/content.php?topic=136\&articleNo=476\&lang=en

Tarhini, A. Hone, K. \& Liu, X. (2015). A cross-cultural examination of the impact of social, organisational and individual factors on educational technology acceptance between British and Lebanese university students. British Journal of Educational Technology, 46, 4, 739-755. doi: 10.1111/bjet.12169

Thabit, T. \& Harjan, S. (2015). EVALUATE E-LEARNING IN IRAQ APPLYING ON AVICENNA CENTRE IN ERBIL. European Scientific Journal, 2, 122-135

UNDP (2015). About Iraq. Retrieved from http://www.iq.undp.org/content iraq/en/home/country info.html

Unwin, T. (2008). Survey of e-Learning in Africa. Based on a Questionnaire Survey of People on the e-Learning Africa Database in 2007. Royal Holloway University of London, United Nations Educational, Scientific and Cultural Organisation. Retrieved from http://www.elearning-africa.com/pdf/survey/elareport_timunwin.pdf 